\title{
Potential of Cellulose Functionalized with Carboxylic Acid as Biosorbent for the Removal of Cationic Dyes in Aqueous Solution
}

\author{
Lucinaldo dos Santos Silva ${ }^{1}$, Jhonatam de Oliveira Carvalho ${ }^{1}$, \\ Roosevelt Delano de Sousa Bezerra ${ }^{2}$, Mateus Soares da Silva ${ }^{3}$, Francisco José Lustosa Ferreira ${ }^{3}$, \\ Josy Anteveli Osajima ${ }^{3}$ and Edson Cavalcanti da Silva Filho ${ }^{3, *}$ \\ 1 Açailândia Campus, Federal Institute of Maranhão, IFMA, Açailândia, MA 65930-000, Brazil; \\ ssdlucinaldo@gmail.com (L.d.S.S.); jhonatam.carvalho@ifma.edu.br (J.d.O.C.) \\ 2 Teresina-Central Campus, Federal Institute of Piauí, IFPI, Teresina, PI 64000-040, Brazil; \\ rooseveltdsb@ifpi.edu.br \\ 3 Interdisciplinary Laboratory for Advanced Materials-LIMAV, UFPI, Teresina, PI 64049-550, Brazil; \\ mateusufpi@gmail.com (M.S.d.S.); franciscojufpi@gmail.com (F.J.L.F.); josy_osajima@yahoo.com.br (J.A.O.) \\ * Correspondence: edsonfilho@ufpi.edu.br; Tel.: +55-86-3221-5710
}

Academic Editor: Janet L. Scott

Received: 27 February 2018; Accepted: 21 March 2018; Published: 23 March 2018

\begin{abstract}
In the last decade, adsorption has been used to minimize the pollution caused by dyes, which represents a serious environmental problem. In this context, this work reports the preparation of phthalic anhydride-modified cellulose ( $\mathrm{PhCel})$, through the reaction of cellulose (Cel) with phthalic anhydride $(\mathrm{Ph})$. The efficiency of the reaction was observed by elemental analysis, Fourier Transform Infrared (FTIR) spectroscopy, X-ray diffraction (XRD) and thermogravimetry/derivative thermogravimetry (TG/DTG). The adsorbent matrix (Cel and PhCel) was used in the removal of crystal violet $(\mathrm{CV})$ and methylene blue $(\mathrm{MB})$ dyes in aqueous medium. In the kinetic study, the experimental data obtained had the best fit to the pseudo-first-order model. In general, the isotherms obtained at different temperatures had a best fit to the model proposed by Langmuir, and the $\mathrm{CV}$ and $\mathrm{MB}$ adsorption process in adsorbent matrixes can be favored strictly by hydrogen bonds and/or electrostatic interactions for $\mathrm{Cel}$ and electrostatic interactions for $\mathrm{PhCel}$.
\end{abstract}

Keywords: cellulose; modification; description; adsorption; cationic dye

\section{Introduction}

In the last decade, studies have been carried out to minimize the pollution caused by industrial effluents, since the legislation is becoming increasingly rigid in relation to the limits of effluent emission into the environment. Among the effluents, anionic [1-3] and cationic [4-7] dyes, which represent a serious environmental problem, can be highlighted, since in many cases these substances show great resistance to chemical, photochemical or biological degradation methods [8]. In addition, pollution from this class of compound damages several biochemical processes in living beings, such as photosynthesis in aquatic environments, that are of fundamental importance for the maintenance of life on Earth [9].

Cationic dyes are widely employed in the dyeing process of leathers, paper and acrylic fibers; this process involves, as a final step, washing in flowing water to remove excess original dye or hydrolyzed dye not attached to the fibers in the previous steps due to low fixing rates. This process discards $10-15 \%$ of the dyes as effluent, polluting the environment and affecting aquatic organisms [3]. 
Violet crystal (CV) and methylene blue (MB), when dumped into the environment, can affect people in a variety of ways, such as when washing, bathing or drinking. These are not biodegradable substances and can cause various diseases and disorders in living organisms, even at low concentrations $[10,11]$. In this context, numerous dye removal techniques have attracted attention from chemists. Many of them are still in the experimental phase, such as precipitation, ion exchange, adsorption, filtration and electrodeposition [12]. Among all the techniques mentioned, adsorption is an important method for removal of dyes in aqueous media $[2,13]$.

Currently, several adsorbents have been used in aqueous dye adsorption processes [14], especially cellulose, which, being the most abundant polysaccharide in Nature, arouses great attention mainly due to the reactivity of its hydroxyl groups [15-17]. Its ability to adsorb dyes can be increased by suitable chemical modification of its surface in order to incorporate organic molecules containing basic groups, mainly those rich in nitrogen, sulfur and oxygen. Almost always this modification involves non-complicated chemical processes, to give a new surface which generates, for example, an ionic and or covalent interaction capacity with dyes in aqueous medium $[18,19]$.

One of the processes studied for the modification of cellulose is based on the synthesis to incorporate in the polymer structure derived from anhydrides, where maleic [6], succinic [17] and phthalic [20] anhydride can be highlighted. This synthesis is important because it can immobilize on the biopolymer carboxylic groups that can increase the adsorption capacity of cationic dyes in aqueous medium. Thus, this work describes the modification of the cellulose surface with phthalic anhydride in the absence of solvent. Cel and PhCel were characterized by elemental analysis, FTIR, XRD, TG/DTG, and determination of carboxylic groups, and applied to the removal of crystal violet and methylene blue dye where $\mathrm{pH}$, time, concentration and temperature were evaluated. Finally, the experimental data were fitted to different physical-chemical isotherm models.

\section{Results and Discussion}

\subsection{Characterization}

After the reaction of the cellulose with phthalic anhydride, the materials (Cel and PhCel) were characterized by elemental analysis of carbon and hydrogen. From this analysis, $46.14 \pm 0.05 \% \mathrm{C}$ and $5.69 \pm 0.08 \% \mathrm{H}$ were obtained in PhCel, differing from the precursor polymer $(41.47 \pm 0.15 \% \mathrm{C}$ and $6.27 \pm 0.1 \% \mathrm{H}$ ). With this, we can observe that there was a significant increase in the percentage of carbon and a significant decrease in the percentage of hydrogen in the modified cellulose when compared to the pure cellulose. In addition, in the determination of carboxyl groups by reverse titration, $0.40 \pm 0.03$ and $3.56 \pm 0.10 \mathrm{mmol} \cdot \mathrm{g}^{-1}$ were determined for $\mathrm{Cel}$ and $\mathrm{PhCel}$, respectively. These differences are related to the incorporation of carboxylic groups in $\mathrm{PhCel}$ according to the reaction scheme proposed in Figure 1i. From these results, we can observe that the amount of acid groups increased by nine times after the proposed modification.

The infrared spectra of $\mathrm{Cel}$ and PhCel are shown in Figure 1ii. The precursor biopolymer in Figure 1ii(a) shows the presence of $\mathrm{OH}$ groups due to the band appearing in the region between 3500 and $3200 \mathrm{~cm}^{-1}$, which are vibrations corresponding to the $\mathrm{OH}$ stretch of the polymer chain $v(\mathrm{CH}-\mathrm{OH})$ and $v\left(\mathrm{CH}_{2}-\mathrm{OH}\right)$. Another important vibration in the cellulose spectrum appearing in the $3000-2800 \mathrm{~cm}^{-1}$ region is attributed more precisely to $v(\mathrm{C}-\mathrm{H})$ of methyl and methylene groups.

The band at $1639 \mathrm{~cm}^{-1}$ corresponds to the deformation of the primary and secondary $\delta-\mathrm{OH}$ hydroxyl groups and the bands in the region $1500-1200 \mathrm{~cm}^{-1}$ correspond to the deformation of the primary and secondary $\delta(\mathrm{CH}-\mathrm{OH})$ hydroxyl groups. The 1169,1110 and $1058 \mathrm{~cm}^{-1}$ bands refer to the $\beta$-1,4-glycosidic ether stretch, $v(\mathrm{C}-\mathrm{O}-\mathrm{C})$ and those below $1000 \mathrm{~cm}^{-1}$ are attributed to the uptake of alcoholic groups of the polymer chain $[2,21]$. 


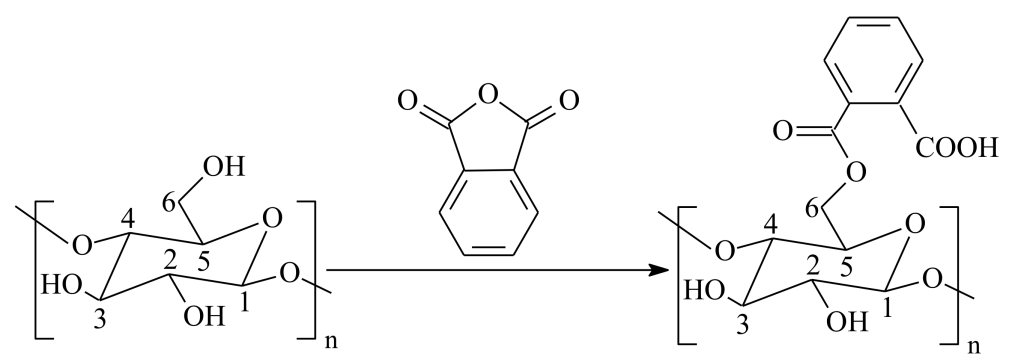

(i)

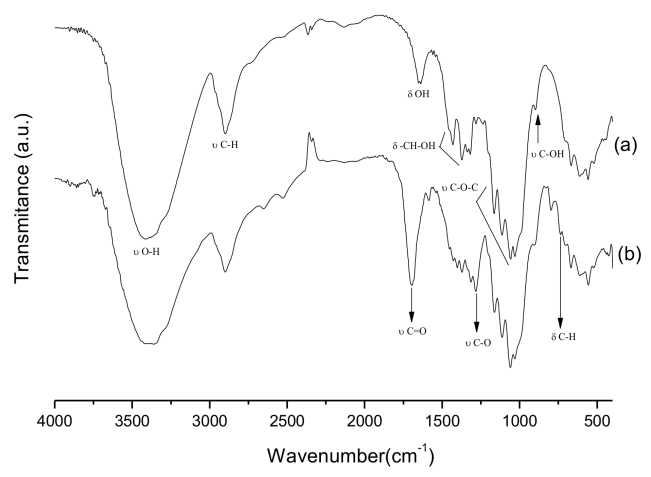

(ii)

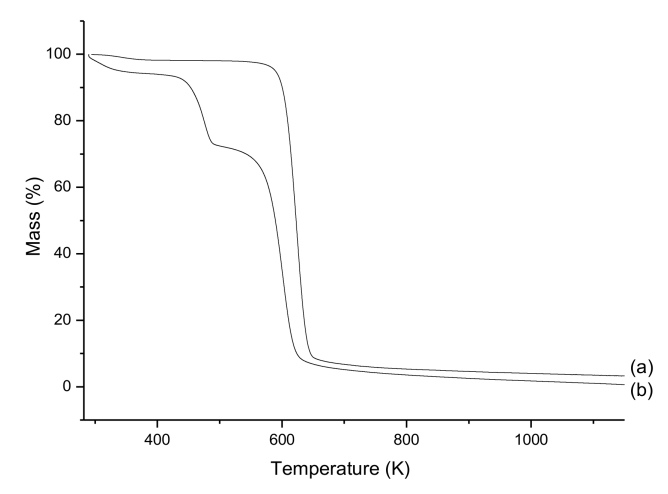

(iv)

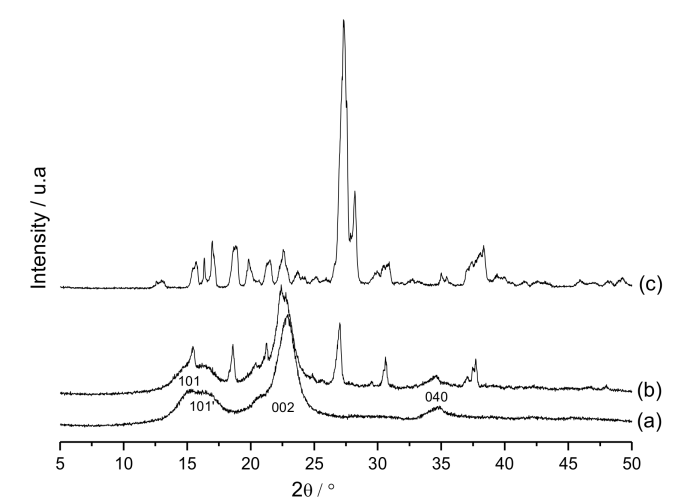

(iii)

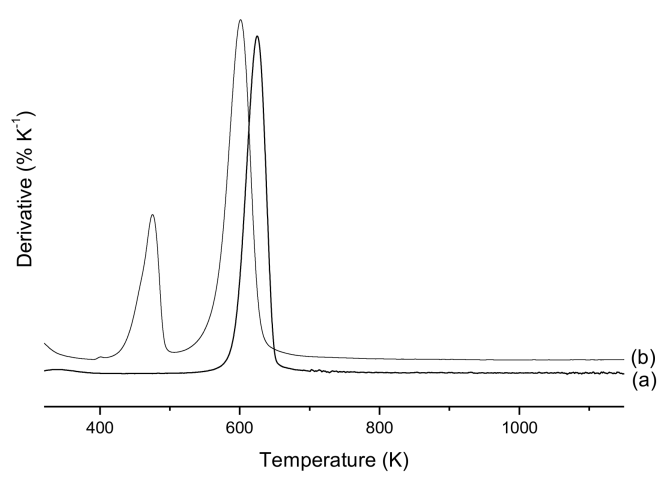

(v)

Figure 1. (i) Reaction scheme of the synthesis process; (ii) Fourier-transform infrared spectra of Cel (a) and PhCel (b); (iii) X-ray diffractograms of Cel (a), PhCel (b) and Ph (c); (iv) TG Curves of Cel (a) and PhCel (b); (v) DTG Curves of Cel (a) and PhCel (b).

When comparing the pure cellulose (Cel) spectrum shown in Figure 1ii(a) to the PhCel spectrum shown in Figure 1ii(b), the bands at 2652 and $2500 \mathrm{~cm}^{-1}$ correspond to the carboxylic acid dimers as do those at $1691 \mathrm{~cm}^{-1} v($ acid $C=O)$, and the appearance of a band at $1280 \mathrm{~cm}^{-1}$ is related to $v(\mathrm{C}-\mathrm{O}$ esters $)$. The band at $745 \mathrm{~cm}^{-1}$ refers to $\delta(\mathrm{C}-\mathrm{H})$ outside the ortho-benzene disubstituted ring of the anhydride group incorporated into the biopolymer structure. The changes of the bands at 1169,1110 and $1058 \mathrm{~cm}^{-1}$ can be explained by a conformational change due to the presence of the modifying groups, which, because of their bulky nature, distort the uniform structure of the cellulose chains, affecting the $\beta-1,4$-glycosidic bond, but without breaking it. The absence of bands at 1800 and $1850 \mathrm{~cm}^{-1}$ confirms that the material obtained is free of unreacted phthalic anhydride. Based on the differences shown, especially the appearance of the carbonyl group and $v($ ester $\mathrm{C}-\mathrm{O})$, we can clearly indicate the binding of the anhydride molecules to the polymer structure of the biopolymer [7,22].

In Figure 1iii, the X-ray diffractograms for $\mathrm{Cel}, \mathrm{PhCel}$ and $\mathrm{Ph}$ are shown. The cellulose used has different peaks characteristic of microcrystalline cellulose: $2 \theta=14.9^{\circ}(101), 16.6^{\circ}\left(101^{\prime}\right), 22.8^{\circ}(002)$ and 
$34.9^{\circ}(040)$. Comparing the diffractograms, the displacement of the $2 \theta$ peak from $22.8^{\circ}$ (Figure 1iii(a)) to $22.3^{\circ}$ (Figure 1iii(b)) and the appearance of the peak $2 \theta=18.5^{\circ}$ (Figure 1iii(b)) can be observed. These changes indicate that the proposed reaction occurred as observed in a similar study [7]. It is important to highlight some peaks in the diffractogram of $\mathrm{PhCel}$ arising from the phthalic anhydride incorporated in the cellulose; these may be related to the $\mathrm{C}-\mathrm{O}-\mathrm{C}$ group attached to the aromatic ring and the polymer chain of the cellulose (see Figure 1i), or could be attributed to a new superstructure formed during the synthesis. The new phase may have been favored because of the presence of the aromatic ring in the modified biopolymer. The aromatic rings have $\pi$-stacking capacity, in which the rings are disposed parallel to one another forming an organized structure in the biopolymer. Indices of this new phase were observed in the infrared spectrum of this material, in which it was possible to observe changes in the bands referring to the $\beta-1,4$-glycosidic bonds. The changes are probably related due to the distortions of the aliphatic ether bond caused by the bulky modifying group, as well as by the tensions they provide in the biopolymer matrix $[7,20]$. The crystallinity index $(\mathrm{CrI})$ proposed by the method of Segal et al. [23], was determined using Equation (1):

$$
\operatorname{CrI}=\frac{\left(I_{002}-I_{a m}\right)}{I_{002}} \times 100
$$

where $I_{002}$ is the intensity of the crystalline portion $\left(22^{\circ}<2 \theta<23^{\circ}\right)$ and $I_{a m}$ is the intensity of the amorphous portion $\left(18^{\circ}<2 \theta<19^{\circ}\right)[6,23]$.

Thus, a CrI for pure cellulose of $74.99 \%$ was obtained, whereas for modified cellulose it was $58.64 \%$. This reduction in the $\mathrm{CrI}$ of the cellulose after the chemical modification accords with the results discussed above, because the proposed reaction can favor the disorganization of the outer chains and probably a decrease in the fiber size, which causes a disturbance in the inter- and intramolecular bonds of hydrogen, generating a new organized structure, thus reducing the crystallinity of the biopolymer.

Figure 1iv shows the thermogravimetric (TG) curves for Cel and PhCel and, in Figure 1v, the derivative TG curves (DTG). We can observe the decomposition of the pure cellulose in a single event, in a temperature range between 536 and $687 \mathrm{~K}$, corresponding to a total mass loss of $91.76 \%$ correlated to adsorbed physical water, condensation of hydroxyls on carbons 2 and 3, and decomposition of the organic structure of the polymer chain. In the biopolymer modified with phthalic anhydride, decomposition occurs in two events; the first event between 410 and $503 \mathrm{~K}$ occurs with a mass loss of $21.35 \%$ corresponding to the loss of incorporated functional groups, and the second between 515 and $672 \mathrm{~K}$ occurs with a loss of mass of $65.55 \%$, related to the decomposition of the organic structure, as observed in most modified biopolymers. It is important to note that the PhCel material favors water adsorption when compared to Cel, due to the fact this material has carboxylic acid groups on its surface. Thus, it can be observed in Figure 1iv that the mass loss related to physsisorbed water for the Cel occurs between 298-414 K with a mass loss of 1.76\%, while the PhCel loss occurs between 298-381 K with a mass loss of 4.07\% [2,6]. The mass losses in PhCel can be observed through the two peaks observed in the DTG curve in Figure 1v.

Figure 2a shows the graph of the zero charge potential of the adsorbent matrices, which shows the behavior of the surface charge of the Cel or PhCel. At pHi 2.0 to 4.0, a small retention of protons occurs in the materials, with a slight increase in the $\mathrm{pH}_{\mathrm{f}}$ value. After $\mathrm{pH}_{\mathrm{i}} 5$, protons retention decreases gradually reaching $\mathrm{pH}_{\mathrm{pzc}}$ (point of zero charge) at 7.30 and 5.30 for $\mathrm{Cel}$ and $\mathrm{PhCel}$, respectively. Above $\mathrm{pH}_{\mathrm{pzc}}$, the surface of the materials begins to release protons into the medium, and consequently the $\mathrm{pH}$ value decreases. This process occurs until around $\mathrm{pH}_{\mathrm{i}} 9.0$ for $\mathrm{Cel}$ and 8.0 for $\mathrm{PhCel}$ and, after this, the attraction of the protons by the surface of the materials begins again, increasing the $\mathrm{pH}$ of the medium $[2,17]$. The difference of the $\mathrm{pH}_{\mathrm{pzc}}$ of the adsorbent matrices can be related to the incorporation of the phthalic anhydride molecule in the cellulose, which generates a surface with carboxylic groups that are easily deprotonated, corroborating to the balance between the charges $\left(\mathrm{pH}_{\mathrm{pzc}}\right)$ occurring at lower $\mathrm{pH}$ in $\mathrm{PhCel}$ when compared to Cel. These results confirm that the $\mathrm{pH}$ of the medium may 
influence the surface of the biopolymers, that is, the ions $\left(\mathrm{H}^{+}\right.$or $\left.\mathrm{OH}^{-}\right)$present in solution may interact with the active sites of the biopolymers, thus altering the charge.

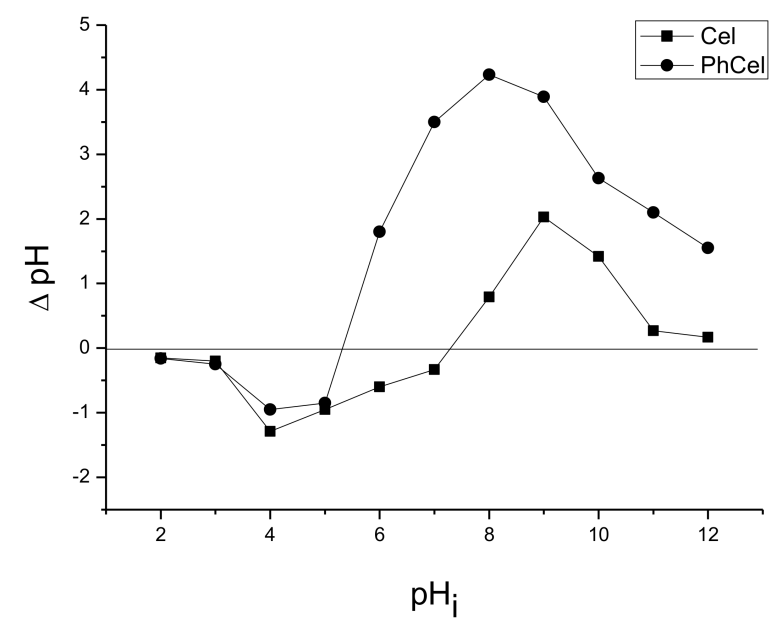

(a)

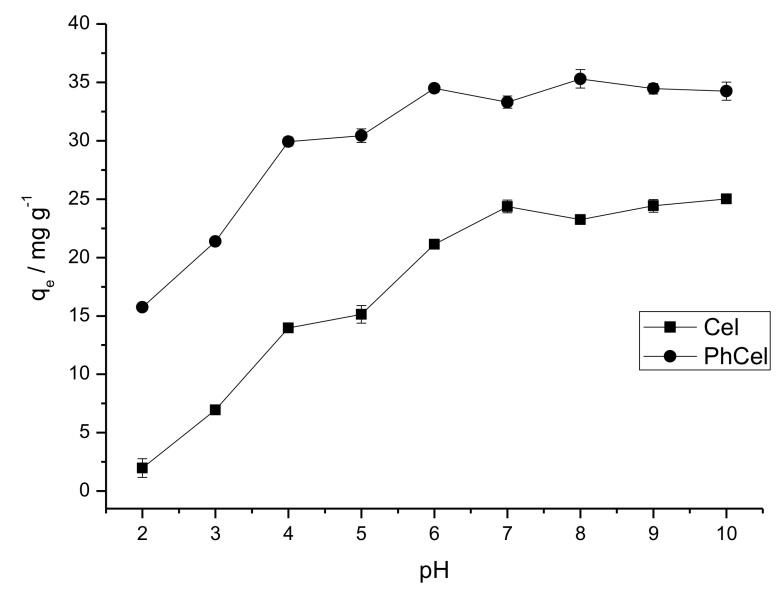

(b)

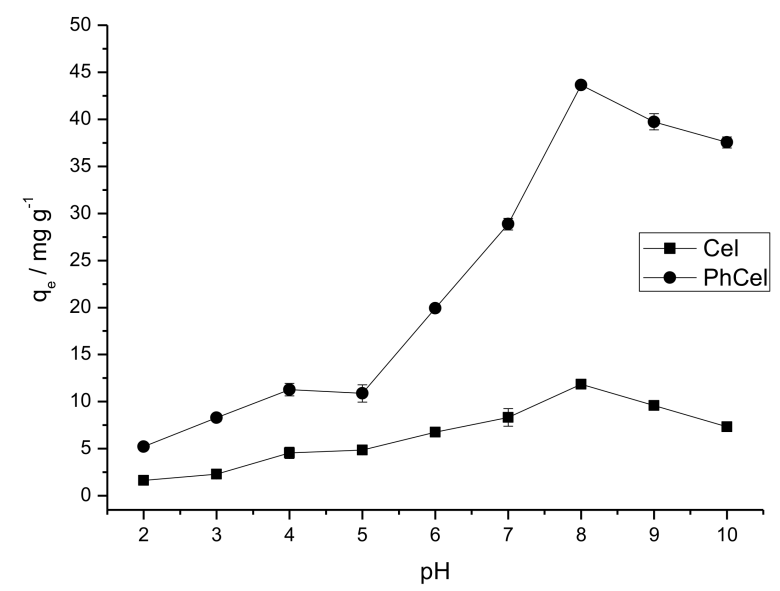

(c)

Figure 2. (a) Point of zero charge of $\mathrm{Cel}$ and PhCel. Effect of $\mathrm{pH}$ on the adsorption of (b) CV and (c) MB onto Cel or PhCel. 


\subsection{Dye Adsorption}

The study of the influence of $\mathrm{pH}$ on adsorption of crystal violet dye (Figure $2 \mathrm{~b}$ ) and methylene blue (Figure 2c) on the surface of $\mathrm{Cel}$ or $\mathrm{PhCel}$, shows that for pure cellulose, the $\mathrm{CV}$ adsorption capacity remains practically constant from $\mathrm{pH}$ 7.0, and for $\mathrm{PhCel}$, from $\mathrm{pH}$ 6.0, a fact observed in a similar study [6]. For adsorption of MB on pure and modified cellulose, the highest capacity was at $\mathrm{pH} 8.0$, as observed in studies similar to this $[24,25]$. Therefore, these $\mathrm{pHs}$ were considered for further studies.

The difference in adsorption capacity of the CV or MB in the adsorbent matrixes at the studied $\mathrm{pHs}$ can be related to the type of interaction between the adsorbent/adsorbate. Thus, correlating the results of $\mathrm{pH}_{\mathrm{pzc}}, \mathrm{pH}$ and microspecies structures (the distributions of the dye microspecies were obtained using MarvinSketch software 15.4.13) of the dye (CV or MB), a reaction scheme was proposed, taking into account the species CV (Figure S1) and MB (Figure S2) in the adsorbent matrixes studied. Figures $\mathrm{S} 1$ and $\mathrm{S} 2$ shows that the Cel being added in the dye solution at different $\mathrm{pHs}$ can increase the amount of protons in the medium, so to retain charge compensation, a negatively charged biopolymer is consequently generated. Therefore, adsorption of the $\mathrm{CV}$ or $\mathrm{MB}$ on $\mathrm{Cel}$, at $\mathrm{pH} 2.0$ and 3.0 can be favored by electrostatic interactions, but the competition between the protons and the dye by the surface of the biopolymer makes the adsorption process difficult, since the protons are smaller and interact more easily with the matrix. At pH 4.0 to 6.0, the adsorption increases because it decreases the degree of competition between protons and the dye in the matrix due to the appearance of hydrogen bonds in the adsorption process. At $\mathrm{pH} 7.0$, adsorption is favored strictly by hydrogen bonds and at basic $\mathrm{pH}$ by electrostatic interactions and/or hydrogen bonds. On the other hand, as the carboxyl group has a pKa of 3.0 [9], at $\mathrm{pH}<3.0$, the higher tendency of this group to be protonated is found to hinder the dye adsorption process (CV or MB) in the PhCel matrix at $\mathrm{pH} 2.0$ and 3.0, since there is practically no electrostatic interaction between the dye and the adsorbent matrix. At $\mathrm{pH} 4.0$ to 10.0, the adsorption capacity increases, being favored by electrostatic interactions between the matrix and the dye due to the difficulty of protonation of the carboxylate group at $\mathrm{pH}>3.0$. The decrease in adsorption capacity of the dye (CV or $\mathrm{MB})$ in the adsorbent matrix may be related to the increase of hydroxyl groups in the medium, generating additional competition between the matrix and these groups by the adsorbate. At extremely basic $\mathrm{pH}(\mathrm{pH} 11.0$ and 12.0), dye precipitation may occur due to a large number of hydroxyl groups in the medium, generating a new dye structure [26]. Therefore, for pure cellulose, adsorption of the dye (CV or $\mathrm{MB})$ can be favored by electrostatic interaction and /or hydrogen bonding and in PhCel is favored strictly by electrostatic interactions [27,28].

In addition, it is important to note that the $\mathrm{pHpzc}$ of $\mathrm{Cel}$ and $\mathrm{PhCel}$ is 7.30 and 5.30, respectively. At $\mathrm{Ph}>\mathrm{pHpzc}$, the surface of the adsorbent releases protons into the medium at $\mathrm{pH}<\mathrm{pHpzc}$, retains protons in the medium. Considering the best $\mathrm{pH}$ for the $\mathrm{CV}$ adsorption process in Cel is $\mathrm{pH}$ $7.0<\mathrm{pHpzc}$, and in PhCel is pH $6.0>\mathrm{pHpzc}$ and adsorption of $\mathrm{MB}$ in Cel and PhCel is pH $8.0>\mathrm{pHpzc}$, the process is favored exclusively, except in the use of the Cel matrix, due to electrostatic interactions between the charged matrix negatively $(\mathrm{pH}>\mathrm{pHpzc})$ and the positively charged dye ( $\mathrm{CV}$ and $\mathrm{MB})$. At $\mathrm{pH}<\mathrm{pHpzc}$, the electrostatic repulsions can occur between the positively charged matrix and the positively charged dye prejudicing the adsorption process, corroborating with the results discussed in Figures S1 and S2 [17,28]. Figure S3 describes the study of the influence of time on the adsorption of crystal violet dye and methylene blue using the Cel or PhCel surface, shows that for pure cellulose, after 100 min contact with crystal violet dye, the amount adsorbed becomes practically constant, which means that for the studied matrix, this time is sufficient for equilibrium between the adsorbent and the adsorbate to be reached. For the adsorption of methylene blue, the equilibration time was $120 \mathrm{~min}$; for the adsorption of $\mathrm{CV}$ using the PhCel matrix, $80 \mathrm{~min}$; and for the adsorption of $\mathrm{MB}, 100 \mathrm{~min}$. The adsorbent/adsorbate equilibrium was observed to be more favorable to electrostatic interactions, as shown in Figures S1 and S2. The experimental results obtained from the study of contact time were submitted to mathematical treatments using different kinetic models (pseudo-first-order [29], 
pseudo-second-order [30] and Elovich [31]), in order to examine the mechanism that determines the adsorption process, as shown in Figure S3.

Table 1 shows the parameters obtained for the fit of the different kinetic models for the systems studied in aqueous medium. For the adsorption of CV on Cel or PhCel, it is observed that the data obtained experimentally had the best fit to the pseudo-second-order model, since the adjustment with this model shows the highest value of the correlation coefficient $\left(R^{2} \geq 0.9838\right)$ compared to the other models, the adsorption of MB in Cel or PhCel, it is observed that the data obtained experimentally had the best fit for the pseudo-first-order model, since the adjustment with this model shows the highest value of the correlation coefficient $\left(R^{2} \geq 0.9845\right)$. Also, analysis shows that the experimentally obtained value of the amount adsorbed per gram of adsorbent, $q_{e, \text { exp }}$, when compared to the values calculated by the equations of the kinetic models, $q_{e, c a l}$, indicates that for pseudo-first-order there is a small discrepancy observing adsorption of $\mathrm{CV}$ or $\mathrm{MB}$ using adsorbent matrices. Thus, the pseudo-first-order model, indicating that diffusion through a boundary precedes the adsorption, is most appropriate to describe the kinetic behavior of the adsorption systems discussed, as has been observed in systems similar to these [32]. Figures S4 and S5 show the adsorption isotherms obtained experimentally, where we observe the temperature does not significantly influence the adsorption of the dye CV (Figure S4) and/or MB (Figure S5) on adsorbent matrices (Cel or PhCel) at temperatures of 298, 308 and $318 \mathrm{~K}$, as observed in similar systems to these [6,7]. The experimental data were adjusted with different isothermal models (Langmuir [33], Freundlich [34] and Temkin [35]), as shown in the Figures S4 and S5. Although the empirical models do not reflect on the issues related to the adsorption mechanism, they provide information on the adsorption capacity of an adsorbent.

Table 2 shows the values of the parameters of the isotherm models for dye adsorption (CV or MB) in aqueous medium. We can observe that the values of the correlation coefficients $\left(R^{2}\right)$, calculated from the nonlinear adjustment to the experimental data by the models, present higher values for the Langmuir model, except for the adsorption isotherm of the CV on PhCel at a temperature of 298 and $308 \mathrm{~K}$, the best fit was the model proposed by Temkin and $318 \mathrm{~K}$, the best fit was the model proposed by Freundlich, as may be observed in the non-linear adjustments shown in Figure S4 (CV) and Figure S5 (MB). For Langmuir model, analyzing the amount of amount adsorbed per gram of adsorbent obtained experimentally, $q_{e, e x p}$, when compared with the values calculated by the equations of the other models, $q_{\max }$, indicates that there is a small discrepancy between the adsorption systems studied. Thus, in general, the experimental data have a better fit to the isotherm model proposed by Langmuir, being the Temkin model closer to the Langmuir model, which describes the adsorption process occurring in a monolayer. For all temperatures in the reaction media considered, $R_{L}$ values are within the range that considers favorable adsorption $\left(0<R_{L}<1\right)$. Although the results of the Freundlich model show relatively low correlation coefficient values for some temperatures in the reaction media studied, this corroborates the spontaneity of the adsorption process, since the values of $n_{f}$ are greater than 1 .

The maximum amount of adsorption of the CV adsorbed on Cel and PhCel was 27.19 and $43.24 \mathrm{mg} \mathrm{g}^{-1}$, respectively, and adsorption of $\mathrm{MB}$ on $\mathrm{Cel}$ and $\mathrm{PhCel}$ was 14.37 and $56.99 \mathrm{mg} \mathrm{g}^{-1}$, respectively. 
Table 1. Modeled kinetic parameters for the adsorption of CV and MB by Cel or PhCel.

\begin{tabular}{|c|c|c|c|c|c|c|c|c|c|c|c|c|c|}
\hline \multirow[b]{2}{*}{ Adsorbent } & \multirow[b]{2}{*}{$\mathrm{pH}$} & \multirow[b]{2}{*}{ Dye } & \multirow{2}{*}{$\begin{array}{c}q_{e, \exp } \\
\left(\mathrm{mg} \mathrm{g}^{-1}\right)\end{array}$} & \multicolumn{3}{|c|}{ Pseudo-First-Order Model } & \multicolumn{4}{|c|}{ Pseudo-Second-Order Model } & \multicolumn{3}{|c|}{ Elovich Model } \\
\hline & & & & $\begin{array}{c}k_{1} \\
\left(\min ^{-1}\right)\end{array}$ & $\begin{array}{c}q_{e, c a l} \\
\left(\mathrm{mg} \mathrm{g}^{-1}\right)\end{array}$ & $R^{2}$ & $\left(\mathrm{~g} \mathrm{mg}^{-1} \min ^{-1}\right)$ & $\begin{array}{c}q_{e, c a l} \\
\left(\mathrm{mg} \mathrm{g}^{-1}\right)\end{array}$ & $\underset{\left(\mathrm{mg} \mathrm{g}^{-1} \min ^{-1}\right)}{h}$ & $R^{2}$ & $\left(\mathrm{mg} \mathrm{g}^{-1} \min ^{-1}\right)$ & $\begin{array}{c}\beta \\
\left(\mathrm{g} \mathrm{mg}^{-1}\right)\end{array}$ & $R^{2}$ \\
\hline \multirow{2}{*}{ Cel } & 7.0 & $\mathrm{CV}$ & 24.7470 & 0.0328 & 24.5225 & 0.9815 & 0.0014 & 28.7321 & 1.1557 & 0.9879 & 3.3022 & 0.1788 & 0.9829 \\
\hline & 8.0 & $\mathrm{MB}$ & 9.6460 & 0.0201 & 10.2337 & 0.9892 & 0.0016 & 12.8901 & 0.2658 & 0.9861 & 0.5198 & 0.3359 & 0.9818 \\
\hline \multirow[b]{2}{*}{ PhCel } & 6.0 & $\mathrm{CV}$ & 34.8730 & 0.0460 & 34.1093 & 0.9795 & 0.0019 & 37.9294 & 2.7334 & 0.9838 & 18.6190 & 0.1769 & 0.9741 \\
\hline & 8.0 & MB & 41.7840 & 0.0262 & 43.5332 & 0.9845 & 0.0005 & 53.2477 & 1.4177 & 0.9661 & 2.8421 & 0.0823 & 0.9512 \\
\hline
\end{tabular}

Table 2. Isotherm model parameters for the adsorption of CV and MB on Cel or PhCel.

\begin{tabular}{|c|c|c|c|c|c|c|c|c|c|c|c|c|c|}
\hline \multirow[b]{2}{*}{ Adsorbent } & \multirow[b]{2}{*}{$\mathrm{pH}$} & \multirow[b]{2}{*}{ Dye } & \multirow[b]{2}{*}{ Temperature (K) } & \multicolumn{4}{|c|}{ Langmuir } & \multicolumn{3}{|c|}{ Freundlich } & \multicolumn{3}{|c|}{ Temkin } \\
\hline & & & & $\begin{array}{c}q_{\max } \\
\left(\mathrm{mg} \mathrm{g}^{-1}\right)\end{array}$ & $\begin{array}{c}K_{L} \\
\left(\mathrm{~L} \mathrm{mg}^{-1}\right)\end{array}$ & $R_{L}$ & $R^{2}$ & $n_{f}$ & $\begin{array}{c}K_{f} \\
\left(\mathrm{~L} \mathrm{~g}^{-1}\right)\end{array}$ & $R^{2}$ & $\begin{array}{c}A_{T} \\
\left(\mathrm{~L} \mathrm{mg}^{-1}\right)\end{array}$ & $\begin{array}{c}b_{T} \\
\left(\mathrm{~J} \mathrm{~mol}^{-1}\right)\end{array}$ & $R^{2}$ \\
\hline \multirow{3}{*}{ Cel } & \multirow{3}{*}{7.0} & \multirow{3}{*}{$\mathrm{CV}$} & 298 & 27.1985 & 0.1403 & 0.1336 & 0.9844 & 3.5521 & 7.8022 & 0.9648 & 1.9197 & 110.1706 & 0.9843 \\
\hline & & & 308 & 26.6632 & 0.1354 & 0.1696 & 0.9700 & 3.7394 & 8.0199 & 0.9541 & 2.6169 & 151.0012 & 0.9690 \\
\hline & & & 318 & 27.0856 & 0.1166 & 0.1538 & 0.9784 & 3.4158 & 7.2187 & 0.9637 & 1.7727 & 166.9936 & 0.9783 \\
\hline \multirow{3}{*}{ Cel } & \multirow{3}{*}{8.0} & \multirow{3}{*}{$\mathrm{MB}$} & 298 & 12.0854 & 0.0671 & 0.2193 & 0.9909 & 2.7744 & 2.1758 & 0.9615 & 0.6367 & 216.2711 & 0.9863 \\
\hline & & & 308 & 14.3716 & 0.0549 & 0.2446 & 0.9886 & 2.4717 & 2.0835 & 0.9558 & 0.5589 & 228.1585 & 0.9811 \\
\hline & & & 318 & 14.1790 & 0.0731 & 0.2240 & 0.9910 & 2.7743 & 2.6760 & 0.9604 & 0.7447 & 278.4868 & 0.9857 \\
\hline \multirow{3}{*}{ PhCel } & \multirow{3}{*}{6.0} & \multirow{3}{*}{$\mathrm{CV}$} & 298 & 37.5097 & 0.2686 & 0.1067 & 0.9682 & 4.0826 & 13.6859 & 0.9666 & 7.6652 & 96.5475 & 0.9790 \\
\hline & & & 308 & 37.1611 & 0.2677 & 0.0881 & 0.9637 & 4.0281 & 13.4287 & 0.9820 & 9.8824 & 126.9822 & 0.9840 \\
\hline & & & 318 & 43.2401 & 0.0696 & 0.2596 & 0.9805 & 2.4657 & 6.8735 & 0.9849 & 1.1053 & 103.9071 & 0.9699 \\
\hline \multirow{3}{*}{ PhCel } & \multirow{3}{*}{8.0} & \multirow{3}{*}{$\mathrm{MB}$} & 298 & 52.2047 & 0.1590 & 0.1885 & 0.9256 & 3.5962 & 16.0065 & 0.8550 & 1.7601 & 53.5470 & 0.8930 \\
\hline & & & 308 & 56.9999 & 0.0847 & 0.2935 & 0.9448 & 2.4163 & 9.4411 & 0.8712 & 0.6308 & 51.7234 & 0.9418 \\
\hline & & & 318 & 55.0383 & 0.1428 & 0.3313 & 0.9567 & 2.8477 & 12.7742 & 0.8709 & 1.2046 & 69.4659 & 0.9360 \\
\hline
\end{tabular}




\section{Materials and Methods}

\subsection{Materials}

Microcrystalline cellulose (Fagron, São Paulo, Brazil), phthalic anhydride (Isofar, Duque de Caxias, Rio de Janeiro, Brazil), hydrochloric acid (Synth, São Paulo, Brazil), sodium hydroxide (Synth, São Paulo, Brazil), potassium nitrate (Química Moderna Ind., Barueri, Brazil), crystal violet dye (Vetec, CI 42555, Duque de Caxias, Rio de Janeiro, Brazil), methylene blue dye (Proquimios, Bangu, Rio de Janeiro, Brazil), deionized water, all of analytical grade, were used without further purification.

\subsection{Modification of Cellulose}

Carboxylic acid group-containing cellulose was obtained by reaction of pure cellulose (Cel) with phthalic anhydride ( $\mathrm{Ph}$ ), this reaction was adapted from the method described by Melo et al. [20]. The cellulose was reacted with phthalic anhydride (ratio of 1:10 m/m) with stirring $(150 \mathrm{rpm})$ at the melt temperature $(405 \pm 5 \mathrm{~K})$ of the anhydride for $1 \mathrm{~h}$ in the absence of solvent, followed by washing with acetone and deionized water to neutral $\mathrm{pH}$ to remove excess reagent and undesirable products. Subsequently, the solid was separated by centrifugation and oven dried for $12 \mathrm{~h}$ at $333 \mathrm{~K}$. The final material was termed PhCel.

\subsection{Determination of Carboxyl Groups Incorporated in Cellulose}

The carboxyl groups incorporated into the cellulose were determined by reverse titration. For this, $0.1 \mathrm{~g}$ of PhCel was treated with $100.0 \mathrm{~mL}$ of $0.01 \mathrm{~mol} \mathrm{~L}^{-1} \mathrm{NaOH}$ solution for $1 \mathrm{~h}$ under constant magnetic stirring. The solid was separated by centrifugation and three aliquots of $20.0 \mathrm{~mL}$ of each of the obtained solutions were titrated with $0.01 \mathrm{~mol} \mathrm{~L}^{-1} \mathrm{HCl}$ solution [36-38]. The concentration of carboxylic groups was calculated using Equation (2):

$$
C_{\mathrm{COOH}}=\frac{\left(C_{\mathrm{NaOH}} V_{\mathrm{NaOH}}\right)-\left(5 C_{\mathrm{HCl}} V_{\mathrm{HCl}}\right)}{m}
$$

where $C_{\mathrm{NaOH}}$ and $\mathrm{C}_{\mathrm{HCl}}$ are the concetration of the initial hydroxide and hydrochloric acid $\left(\mathrm{mol} \mathrm{L}^{-1}\right)$, $V_{\mathrm{NaOH}}$ and $V_{\mathrm{HCl}}$ are the volumes of the initial hydroxide and hydrochloric acid (L) used in the titration of unreacted excess with the base and $m(\mathrm{~g})$ is the mass of the chemically modified material.

\subsection{Zero Point of Charge $\left(\mathrm{pH}_{\mathrm{pzc}}\right)$}

The zero point of charge of the matrixes was determined using the solids addition method [2,17]. A $20.0 \mathrm{~mL}$ volume of $0.1 \mathrm{~mol} \mathrm{~L}{ }^{-1}$ solution of $\mathrm{KNO}_{3}$ was added to a series of beakers. The $\mathrm{pH}$ of the solution in each vessel was adjusted with $\mathrm{HCl}\left(0.1 \mathrm{~mol} \mathrm{~L}^{-1}\right)$ and / or $\mathrm{NaOH}\left(0.1 \mathrm{~mol} \mathrm{~L}^{-1}\right)$ to $\mathrm{pH} 2.0$ to 12.0 and the initial $\mathrm{pH}$ of each solution, $\mathrm{pH}_{\mathrm{i}}$, was measured. To $20.0 \mathrm{~mL}$ of each $\mathrm{KNO}_{3}$ solution was added $20.0 \mathrm{mg}$ of the PhCel or Cel matrix. The suspension was stirred (140 rpm) for $24 \mathrm{~h}$ at room temperature. After that time, the final $\mathrm{pH}$ value of the solution, $\mathrm{pH}_{\mathrm{f}}$, was measured. The difference between the initial and final $\mathrm{pH}$ was calculated: $\Delta \mathrm{pH}=\mathrm{pH}_{\mathrm{i}}-\mathrm{pH}_{\mathrm{f}}$, and the $\Delta \mathrm{pH}$ plotted as a function of $\mathrm{pH}_{\mathrm{i}}$. The $\mathrm{pH}_{\mathrm{i}}$ value with $\Delta \mathrm{pH}$ equal to zero is called the zero point of charge, $\mathrm{pH}_{\mathrm{pzc}}$, of the material.

\subsection{Characterization}

The elemental CHN analyses of the samples were recorded using a (Perkin Elmer, Waltham, MA, USA) 2400 Series II instrument. The FTIR spectra were recorded on a MB series FTIR spectrophotometer (Bomem, Ville de Québec, QC, Canada), in transmittance mode with the use of $\mathrm{KBr}$ pellets. Measurements were taken in the wavenumber range of $400 \mathrm{~cm}^{-1}$ to $4000 \mathrm{~cm}^{-1}$, with 32 scans and $4 \mathrm{~cm}^{-1}$ resolution. XRD measurements were carried out with a XRD600A diffractometer (Shimadzu, Kyoto, Japan) equipped with Cu-target tube at wavelength $\lambda=0.1540 \mathrm{~nm}$. Diffractograms were collected at $2 \theta$ ranging from $5^{\circ}$ to $50^{\circ}$ at a rate of $5^{\circ} \mathrm{min}^{-1}$. Thermogravimetric analyses 
(TG/DTG) were recorded using a Q600 V20.9 Build TA instrument (TA instrument, New Castle, DE, USA) in the temperature range of $25-1000{ }^{\circ} \mathrm{C}$ at a rate of $10{ }^{\circ} \mathrm{C} \mathrm{min}-1$ under an argon flow rate of $100 \mathrm{~mL} \mathrm{~min}^{-1}$. Absorbance readings were performed in triplicate on an Cary $60 \mathrm{UV}$-Vis spectrophotometer (Agilent Technologies, Santa Clara, CA, USA), at wavelength with maximum absorption at $581 \mathrm{~nm}$ for crystal violet (CV) and $665 \mathrm{~nm}$ for methylene blue (MB) colorant and the reported mean values.

\subsection{Dye Adsorption}

\subsubsection{Effect of $\mathrm{pH}$}

The initial $\mathrm{pH}$ variation of the dye solution was studied. For this study, a solution of concentration $100.0 \mathrm{mg} \mathrm{L}^{-1}$ of the dye (CV or $\left.\mathrm{MB}\right)$ in the $\mathrm{pH}$ range of 2.0 to 10.0 was used. A pH below 2.0 causes the dye solution to change color. A pH above 10.0 causes precipitation to form in the solution. Then, $20.0 \mathrm{~mL}$ of dye solution, with $\mathrm{pH}$ in the above range, was contacted with $20.0 \mathrm{mg}$ of the matrixes (Cel or PhCel) under stirring (140 rpm) at $298 \mathrm{~K}$ in the best time for the adsorption process. After this time, the mixture was centrifuged, aliquots withdrawn from the supernatant solution and the amount of dye remaining determined by absorbance readings. The amount of dye retained in the adsorbent, $q_{e}\left(\mathrm{mg} \mathrm{g}^{-1}\right)$, at each $\mathrm{pH}$, was calculated using Equation (3). The results showed the optimum pHs for adsorbent matrixes in adsorption processes $[25,39,40]$ :

$$
q_{e}=\frac{\left(C_{i}-C_{e}\right) V}{m}
$$

where $C_{i}$ is the initial concentration of the dye $\left(\mathrm{mg} \mathrm{L}^{-1}\right), C_{e}$ is the equilibrium concentration of the dye $\left(\mathrm{mg} \mathrm{L}^{-1}\right), m$ is the mass of the adsorbent $(\mathrm{g})$ and $V$ is the volume of the dye solution (L).

\subsubsection{Effect of Time}

For the contact time study performed at the best adsorption $\mathrm{pH}$ of the biopolymers, $20.0 \mathrm{~mL}$ of $100.0 \mathrm{mg} \mathrm{L}^{-1}$ (CV or MB) dye solution was placed in contact with $20.0 \mathrm{mg}$ of the Cel or PhCel matrix. This system was kept under stirring $(140 \mathrm{rpm}$ ) at a temperature of $298 \mathrm{~K}$ for different times in the range of 0 to $240 \mathrm{~min}$. the mixtures were centrifuged, aliquots withdrawn from the supernatant solution and the amount of remaining dye determined by absorbance readings. The amount of dye retained, $q_{e}\left(\mathrm{mg} \mathrm{g}^{-1}\right)$ in the adsorbent, for each time, was calculated using Equation (3). The results showed the times required to achieve the maximum adsorption of the adsorbents used [32,41,42]. The experimental data were studied with pseudo-first-order [29], pseudo-second-order [30] and Elovich [31] equations to verify the kinect of the adsorption process. For the nonlinear adjustment of the time isotherm to the pseudo-first-order model the Equation (4) is used in the non-linear form developed by Lagergren [29]:

$$
q_{t}=q_{e, c a l}\left[1-\exp \left(-k_{1} t\right)\right]
$$

where $q_{e, \operatorname{exp~ou~cal~}}\left(\mathrm{mg} \mathrm{g}^{-1}\right)$ is the amount adsorbed per gram of adsorbent, $q_{t}\left(\mathrm{mg} \mathrm{g}^{-1}\right)$ is the amount adsorbed per gram of adsorbent in the time $t(\mathrm{~min})$ and $k_{1}\left(\mathrm{~min}^{-1}\right)$ is the pseudo-first-order adsorption rate constant [29].

The nonlinear adjustment of the experimental data using the pseudo-second-order model, developed by Ho and McKay [30], can be performed using Equation (5) and the initial adsorption rate, $h\left(\mathrm{mg} \mathrm{g}^{-1} \mathrm{~min}^{-1}\right)$, when $t=0$ can be obtained by Equation (6):

$$
\begin{gathered}
q_{t}=\frac{k_{2} q_{e, \mathrm{cal}^{2}} t}{1+q_{e, \mathrm{cal}} k_{2} t} \\
h=k_{2} q_{e, \mathrm{cal}}{ }^{2}
\end{gathered}
$$


where $k_{2}\left(\mathrm{~g} \mathrm{mg}^{-1} \mathrm{~min}^{-1}\right)$ is the pseudo-second-order rate constant [30]. The Elovich model [31], represented by Equation (7), is suitable for systems whose adsorption surfaces are heterogeneous and show different activation energies in the chemisorption process:

$$
q_{t}=\frac{1}{\beta} \ln (\alpha \beta t)
$$

where $\beta\left(\mathrm{g} \mathrm{mg}^{-1}\right)$ is the adsorption constant related to the degree of coverage of the adsorbent surface and the activation energy of the chemisorption process, $\alpha\left(\mathrm{mg} \mathrm{g}^{-1} \mathrm{~min}^{-1}\right)$ is the initial adsorption velocity constant and $q_{t}\left(\mathrm{mg} \mathrm{g}^{-1}\right)$ is the amount adsorbed at time $t(\mathrm{~min})$ [31].

\subsubsection{Effect of Dye Concentration and Temperature}

In the study of the influence of the concentration on the adsorption process, $20.0 \mathrm{mg}$ of the matrices (Cel or PhCel) was placed in contact with $20.0 \mathrm{~mL}$ of dye solution (CV or MB) at different concentrations in the range of 0 to $100.0 \mathrm{mg} \mathrm{L}^{-1}$, at the optimum $\mathrm{pH}$ and for the optimum times for adsorption. The system was kept under stirring (140 rpm) at different temperatures (298, 308 and $318 \mathrm{~K})$. After the optimum times, the mixtures were centrifuged, aliquots removed from the supernatant solution and the absorbances read. The amount of dye retained in the adsorbent, $q_{e}\left(\mathrm{mg} \mathrm{g}^{-1}\right)$, at each concentration was calculated using Equation (3). The adjustment of the experimental data of the concentration isotherms was performed using the isothermal nonlinear models of Langmuir [33], Freundlich [34] and Temkin [35].

For the adjustment of the experimental concentration isotherm to the model proposed by Langmuir [33], Equation (8) is used in the nonlinear form. The parameters of the Langmuir equation can be expressed in terms of a dimensionless separation factor, $R_{L}$, defined by Equation (9), which can then evaluate the isotherm shape and the spontaneity of the adsorption process: $R_{L}>1$ (unfavorable adsorption process), $R_{L}=1$ (linear adsorption process), $0<R_{L}<1$ (favorable adsorption process) and $R_{L}=0$ (irreversible adsorption process) [33]:

$$
\begin{aligned}
q_{e} & =\frac{K_{L} q_{\max } C_{e}}{1+K_{L} C_{e}} \\
R_{L} & =\frac{1}{1+K_{L} C_{e}}
\end{aligned}
$$

where $q_{e}\left(\mathrm{mg} \mathrm{g}^{-1}\right)$ is the equilibrium adsorption capacity, $C_{e}\left(\mathrm{mg} \mathrm{L}^{-1}\right)$ is the equilibrium concentration of the dye, $q_{\max }\left(\mathrm{mg} \mathrm{g}^{-1}\right)$ is the maximum amount of theoretical adsorption at equilibrium and $K_{L}$ $\left(\mathrm{L} \mathrm{mg}^{-1}\right)$ is Langmuir constant [33].

The adjustment of the experimental data using the Freundlich model [34] can be evaluated using Equation (10) in the nonlinear form:

$$
q_{e}=K_{f} C_{e}\left(1 / n_{f}\right)
$$

where $q_{e}$ and $C_{e}$ have the same meaning as in the Langmuir equation, $K_{f}\left(\mathrm{~L} \mathrm{~g}^{-1}\right)$ is a constant related to the adsorption capacity and $n_{f}$ is a constant related to the adsorption intensity and the spontaneity of the adsorption, when this value is greater than 1 . The experimental data can be adjusted to the Temkin model [35] using Equation (11) in nonlinear form:

$$
q_{e}=\frac{R T}{b_{T}} \ln \left(A_{T} C_{e}\right)
$$

where $q_{e}$ and $C_{e}$ have the same meaning as in the Langmuir equation, $T(\mathrm{~K})$ is the temperature, $R\left(8.314 \mathrm{~J} \mathrm{~mol}^{-1} \mathrm{~K}^{-1}\right)$ is the gas constant, $A_{T}\left(\mathrm{~L} \mathrm{mg}^{-1}\right)$ and $b_{T}\left(\mathrm{~J} \mathrm{~mol}^{-1}\right)$ are the isotherm constant and Temkin constant, respectively [35]. 


\section{Conclusions}

In the search for matrixes that could be used in the removal of cationic dyes in aqueous solution, the reaction to obtain the phthalic anhydride-modified cellulose matrix (PhCel) was confirmed by product characterization (elemental analysis, FTIR, XRD, TG/DTG and determination of carboxylic acid groups). In the adsorption tests carried out using $20.0 \mathrm{mg}$ of the adsorbent matrix and $20.0 \mathrm{~mL}$ of the dye solution (CV or MB), the PhCel matrix was efficient in the adsorption of $\mathrm{CV}$ or $\mathrm{MB}$ in aqueous medium when compared to the pure biopolymer (Cel).

In the time study, the data obtained experimentally had the best fit to a pseudo-first-order model. The concentration isotherms obtained had the best fit to the model proposed by Langmuir, at temperatures of 298,308 and $318 \mathrm{~K}$, except for the adsorption isotherm of the CV on PhCel at a temperature of 298 and $308 \mathrm{~K}$, where the best fit was to the model proposed by Temkin and $318 \mathrm{~K}$, where the best fit was the model proposed by Freundlich. The adsorption capacities of CV on Cel (pH 7.0 and $100 \mathrm{~min}$ ) and $\mathrm{PhCel}\left(\mathrm{pH} 6.0\right.$ and $80 \mathrm{~min}$ ) were 27.19 and $43.24 \mathrm{mg} \mathrm{g}^{-1}$, respectively, and the adsorptions of $\mathrm{MB}$ on $\mathrm{Cel}(\mathrm{pH} 8.0$ and $120 \mathrm{~min}$ ) and $\mathrm{PhCel}(\mathrm{pH} 8.0$ and $100 \mathrm{~min}$ ) were 14.37 and $56.99 \mathrm{mg} \mathrm{g}^{-1}$, respectively.

The adsorption of the CV or MB dye on PhCel can be favored strictly by electrostatic interactions in comparison with Cel, in which the adsorption can be favored by electrostatic interactions and/or hydrogen bonds. Therefore, $\mathrm{Cel}$ and PhCel can be used in the removal of CV or MB dyes in the environment, since these materials have good adsorption capacity.

Supplementary Materials: The following are available online, Figure S1: (i) Distribution of CV microspecies under different $\mathrm{pHs}$. Scheme of adsorption process of $\mathrm{CV}$ in the (ii) Cel and (iii) PhCel under different $\mathrm{pHs}$, Figure S2: (i) Distribution of MB microspecies under different $\mathrm{pHs}$. Scheme of adsorption process of $\mathrm{MB}$ in the (ii) Cel and (iii) PhCel under different pHs, Figure S3: Effect of contact time on the adsorption of CV (a and b) and MB (c and d) onto Cel (- -) or PhCel (- -) and the nonlinear adjustments of kinetic models, Figure S4: Effect of $C V$ concentration on the adsorption process in the Cel $(a-c)$ or PhCel $(d-f)$ in different temperatures and the nonlinear adjustments of Isotherm models, Figure S5: Effect of MB concentration on the adsorption process in the $\mathrm{Cel}(\mathrm{a}-\mathrm{c})$ or PhCel $(\mathrm{d}-\mathrm{f})$ in different temperatures and the nonlinear adjustments of Isotherm models.

Acknowledgments: The authors thank the Coordination Support in Higher Education (CAPES), the National Council for Scientific and Technological Development (CNPq) and the Foundation of Support for Research of Piauí (FAPEPI) for financial support, and the Federal University of Piauí (UFPI) and Federal Institute of Maranhão (IFMA), for providing research facilities.

Author Contributions: L.d.S.S., J.d.O.C., R.D.d.S.B., M.S.d.S. and F.J.L.F. performed the experimental part, performed the literature review, writing the manuscript, discussion, interpretation of data. J.A.O. and E.C.d.S.F. performed the literature review, writing the manuscript, discussion, interpretation of data and corrected the paper.

Conflicts of Interest: The authors declare no conflict of interest.

\section{References}

1. Ruan, C.; Strømme, M.; Lindh, J. Preparation of porous 2,3-dialdehyde cellulose beads crosslinked with chitosan and their application in adsorption of Congo red dye. Carbohydr. Polym. 2018, 181, $200-207$. [CrossRef] [PubMed]

2. Silva, L.S.; Lima, L.C.B.; Silva, F.C.; Matos, J.M.E.; Santos, M.R.M.C.; Santos Júnior, L.S.; Sousa, K.S.; Silva Filho, E.C. Dye anionic sorption in aqueous solution onto a cellulose surface chemically modified with aminoethanethiol. Chem. Eng. J. 2013, 218, 89-98. [CrossRef]

3. Wang, L.; Li, J. Adsorption of C.I. Reactive Red 228 dye from aqueous solution by modified cellulose from flax shive: Kinetics, equilibrium, and thermodynamics. Ind. Crops Prod. 2013, 42, 153-158. [CrossRef]

4. Jiang, F.; Dinh, D.M.; Hsieh, Y. Adsorption and desorption of cationic malachite green dye on cellulose nanofibril aerogels. Carbohydr. Polym. 2017, 173, 286-294. [CrossRef] [PubMed]

5. Silva, F.C.; Silva, M.M.F.; Lima, L.C.B.; Osajima, J.A.; Silva Filho, E.C. Integrating chloroethyl phosphate with biopolymer cellulose and assessing their potential for absorbing brilliant green dye. J. Environ. Chem. Eng. 2016, 4, 3348-3356. [CrossRef] 
6. Qiao, H.; Zhou, Y.; Yu, F.; Wang, E.; Min, Y.; Huang, Q.; Pang, L.; Ma, T. Effective removal of cationic dyes using carboxylate-functionalized cellulose nanocrystals. Chemosphere 2015, 141, 297-303. [CrossRef] [PubMed]

7. Zhou, Y.; Min, Y.; Qiao, H.; Huang, Q.; Wang, E.; Ma, T. Improved removal of malachite green from aqueous solution using chemically modified cellulose by anhydride. Int. J. Biol. Macromol. 2015, 74, 271-277. [CrossRef] [PubMed]

8. Chaudhuri, H.; Dash, S.; Ghorai, S.; Pal, S.; Sarkar, A. SBA-16: Application for the removal of neutral, cationic, and anionic dyes from aqueous medium. J. Environ. Chem. Eng. 2016, 4, 157-166. [CrossRef]

9. Gong, R.; Jin, Y.; Chen, F.; Chen, J.; Liu, Z. Enhanced malachite green removal from aqueous solution by citric acid modified rice straw. J. Hazard. Mater. 2006, 137, 865-870. [CrossRef] [PubMed]

10. Guzel, F.; Saygili, H.; Saygili, G.A.; Koyuncu, F. Decolorisation of aqueous crystal violet solution by a new nanoporous carbon: Equilibrium and kinetic approach. J. Ind. Eng. Chem. 2014, 20, 3375-3386. [CrossRef]

11. Peydayesh, M.; Rahbar-Kelishami, A. Adsorption of methylene blue onto Platanus orientalis leaf powder: Kinetic, equilibrium and thermodynamic studies. J. Ind. Eng. Chem. 2015, 21, 1014-1019. [CrossRef]

12. Salleh, M.A.M.; Mahmoud, D.K.; Karim, W.A. W.A.; Idris, A. Cationic and anionic dye adsorption by agricultural solid wastes: A comprehensive review. Desalination 2011, 280, 1-13. [CrossRef]

13. Silva, L.S.; Lima, L.C.B.; Ferreira, F.J.L.; Silva, M.S.; Osajima, J.A.; Bezerra, R.D.S.; Silva Filho, E.C. Sorption of the anionic reactive red RB dye in cellulose: Assessment of kinetic, thermodynamic, and equilibrium data. Open Chem. 2015, 13, 801-812. [CrossRef]

14. Gupta, V.K.; Suhas. Application of low-cost adsorbents for dye removal-A review. J. Environ. Manag. 2009, 90, 2313-2342. [CrossRef] [PubMed]

15. Bezerra, R.D.S.; Morais, A.I.S.; Osajima, J.A.; Nunes, L.C.C.; Silva Filho, E.C. Development of new phosphated cellulose for application as an efficient biomaterial for the incorporation/release of amitriptyline. Int. J. Biol. Macromol. 2016, 86, 362-375. [CrossRef] [PubMed]

16. Silva Filho, E.C.; Melo, J.C. P.; Airoldi, C. Preparation of ethylenediamine-anchored cellulose and determination of thermochemical data for the interaction between cations and basic centers at the solid/liquid interface. Carbohydr. Res. 2006, 341, 2842-2850. [CrossRef] [PubMed]

17. Vieira, A.P.; Santana, S.A.A.; Bezerra, C.W.B.; Silva, H.A.S.; Melo, J.C.P.; Silva Filho, E.C.; Airoldi, C. Copper sorption from aqueous solutions and sugar cane spirits by chemically modified babassu coconut (Orbignya speciosa) mesocarp. Chem. Eng. J. 2010, 161, 99-105. [CrossRef]

18. Kumari, S.; Mankotia, D.; Chauhan, G.S. Crosslinked cellulose dialdehyde for congo red removal from its aqueous solutions. J. Environ. Chem. Eng. 2016, 4, 1126-1136. [CrossRef]

19. Vieira, A.P.; Santana, S.A.A.; Bezerra, C.W.B.; Silva, H.A.S.; Chaves, J.A.P.; Melo, J.C.P.; Silva Filho, E.C.; Airoldi, C. Kinetics and thermodynamics of textile dye adsorption from aqueous solutions using babassu coconut mesocarp. J. Hazard. Mater. 2009, 166, 1272-1278. [CrossRef] [PubMed]

20. Melo, J.C.P.; Silva Filho, E.C.; Santana, S.A.A.; Airoldi, C. Exploring the favorable ion-exchange ability of phthalylated cellulose biopolymer using thermodynamic data. Carbohydr. Res. 2010, 345, 1914-1921. [CrossRef] [PubMed]

21. Silva Filho, E.C.; Silva, L.S.; Lima, L.C.B.; Santos Junior, L.S.; Santos, M.R.M.C.; Matos, J.M.E.; Airoldi, C. Thermodynamic data of 6-(4'-aminobutylamino)-6-deoxycellulose sorbent for cation removal from aqueous solutions. Sep. Sci. Technol. 2011, 46, 2566-2574. [CrossRef]

22. Pavia, D.L.; Lampman, G.M.; Kriz, G.S.; Vyvyan, J.A. Introduction to Spectroscopy, 4th ed.; Broks Cole: Philadelphia, PA, USA, 2009.

23. Segal, L.; Creely, J.J.; Martin, A.E., Jr.; Conrad, C.M. An empirical method for estimating the degree of crystallinity of native cellulose using the X-ray diffractometer. Text. Res. J. 1959, 29, 786-794. [CrossRef]

24. Kumar, K.V.; Ramamurthi, V.; Sivanesan, S. Modeling the mechanism involved during the sorption of methylene blue onto fly ash. J. Colloid Interface Sci. 2005, 284, 14-21. [CrossRef] [PubMed]

25. Zhou, Y.; Jin, Q.; Hu, X.; Zhang, Q.; Ma, T. Heavy metal ions and organic dyes removal from water by cellulose modified with maleic anhydride. J. Mater. Sci. 2012, 47, 5019-5029. [CrossRef]

26. Cotoruelo, L.M.; Marqués, M.D.; Díaz, F.J.; Rodríguez-Mirasol, J.; Rodríguez, J.J.; Cordero, T. Lignin-based activated carbons as adsorbents for crystal violet removal from aqueous solutions. Environ. Prog. Sustain. Energy 2012, 31, 386-396. [CrossRef] 
27. Chakraborty, S.; Chowdhury, S.; Saha, P.D. Adsorption of crystal violet from aqueous solution onto $\mathrm{NaOH}-$ modified rice husk. Carbohydr. Polym. 2011, 86, 1533-1541. [CrossRef]

28. Yan, H.; Zhang, W.; Kan, X.; Dong, L.; Jiang, Z.; Li, H.; Yang, H.; Cheng, R. Sorption of methylene blue by carboxymethyl cellulose and reuse process in a secondary sorption. Colloid Surf. A 2011, 380, 143-151. [CrossRef]

29. Lagergren, S. About the theory of so-called adsorption of soluble substances. K. Sven. Vetenskapsakad. Handl. 1898, 24, 1-39.

30. Ho, Y.S.; Mckay, G. Kinetic models for the sorption of dye from aqueous solution by wood. Process Saf. Environ. 1998, 76, 183-191. [CrossRef]

31. Aharoni, C.; Tompkins, F.C. Kinetics of adsorption and desorption and the Elovich equation. Process Saf. Environ. 1970, 21, 1-49.

32. Santos, C.C.; Mouta, R.; Junior, M.C.C.; Santana, S.A.A.; Silva, H.A.S.; Bezerra, C.W.B. Chitosan-edible oil based materials as upgraded adsorbents for textile dyes. Carbohydr. Polym. 2018, 15, 182-191. [CrossRef] [PubMed]

33. Langmuir, I. The constitution and fundamental properties of solids and liquids. J. Am. Chem. Soc. 1916, 38, 2221-2295. [CrossRef]

34. Freundlich, H.M.F. Uber die adsorption in lösungen. Z. Phys. Chem. 1906, 57, 385-470. [CrossRef]

35. Temkin, M.I.; Pyzhev, V. Kinetics of ammonia synthesis on promoted iron catalyst. Acta Phys. Chim. 1940, 12, 327-356.

36. Gurgel, L.V.A.; Freitas, R.P.; Gil, L.F. Adsorption of $\mathrm{Cu}(\mathrm{II}), \mathrm{Cd}(\mathrm{II})$, and $\mathrm{Pb}(\mathrm{II})$ from aqueous single metal solutions by sugarcane bagasse and mercerized sugarcane bagasse chemically modified with succinic anhydride. Carbohydr. Polym. 2008, 74, 922-929. [CrossRef]

37. Martins, L.R.; Rodrigues, J.A.V.; Adarme, O.F.H.; Melo, T.M.S.; Gurgel, L.V.A.; Gil, L.F. Optimization of cellulose and sugarcane bagasse oxidation: Application for adsorptive removal of crystal violet and auramine-O from aqueous solution. J. Colloid Interface Sci. 2017, 494, 223-241. [CrossRef] [PubMed]

38. Zhou, Y.; Zhang, M.; Hu, X.; Wang, X.; Niu, J.; Ma, T. Adsorption of cationic dyes on a cellulose-based multicarboxyl adsorbent. J. Chem. Eng. Data 2013, 58, 413-421. [CrossRef]

39. El-Sayed, G.O. Removal of methylene blue and crystal violet from aqueous solutions by palm kernel fiber. Desalination 2011, 272, 225-232. [CrossRef]

40. Lin, Q.; Gao, M.; Chang, J.; Ma, H. Adsorption properties of crosslinking carboxymethyl cellulose grafting dimethyldiallylammonium chloride for cationic and anionic dyes. Carbohydr. Polym. 2016, 20, 283-294. [CrossRef] [PubMed]

41. Zhang, L.; Zhang, H.; Guo, W.; Tian, Y. Removal of malachite green and crystal violet cationic dyes from aqueous solution using activated sintering process red mud. Appl. Clay Sci. 2014, 93, 85-93. [CrossRef]

42. Zhou, C.; Wu, Q.; Lei, T.; Negulescu, I.I. Adsorption kinetic and equilibrium studies for methylene blue dye by partially hydrolyzed polyacrylamide/cellulose nanocrystal nanocomposite hydrogels. Chem. Eng. J. 2014, 251, 17-24. [CrossRef]

Sample Availability: Not available. 